European journal of American studies

\title{
Affect and Gender in Cormac McCarthy's Outer Dark
}

Julia Tulloh Harper

\section{(2) OpenEdition}

Journals

Electronic version

URL: https://journals.openedition.org/ejas/12317

DOI: $10.4000 /$ ejas. 12317

ISSN: 1991-9336

Publisher

European Association for American Studies

\section{Electronic reference}

Julia Tulloh Harper, "Affect and Gender in Cormac McCarthy's Outer Dark", European journal of American studies [Online], 12-3 | 2017, Online since 18 December 2017, connection on 08 July 2021. URL: http:// journals.openedition.org/ejas/12317 ; DOl: https://doi.org/10.4000/ejas. 12317

This text was automatically generated on 8 July 2021.

Creative Commons License 


\title{
Affect and Gender in Cormac McCarthy's Outer Dark
}

\author{
Julia Tulloh Harper
}

1 In "The Evolution of the Dead Girlfriend Motif in Outer Dark and Child of God" (2000), Nell Sullivan describes Rinthy Holme, the female protagonist of Cormac McCarthy's second novel, Outer Dark (1968), as a "narrative force to be reckoned with" (70). "Force" is an interesting term, which denotes strength, movement, energy, and compulsion; it emphasizes dynamism rather than stasis, power rather than passivity. In some ways it is obvious why Rinthy might be described in such a way. She is the only female character in McCarthy's entire oeuvre as yet who is a true protagonist, in that she has her own storyline and, as Sullivan observes, does not function as a plot device or catalyst for male action (68). But in other ways, Rinthy is an unlikely candidate for generating a narrative "force"-at least in terms of her characterization. Rinthy is highly vulnerable. She is poor, homeless, and not yet physically recovered from giving birth; her baby is also a product of incest with her brother, Culla, and those who discover this fact have little respect for her. She is also profoundly alone in the world, since Culla has abandoned her, as well as having abducted and abandoned the baby. Rinthy knows no one else, and ceaselessly wanders the land searching for her lost son. Her own personality is also not particularly forceful-she is generally meek, nonconfrontational, quiet, and unobtrusive. Sullivan notes that Rinthy is also characterized by a range of details that appear to limit her agency, such as her doll-like appearance, her association with animals, and the grotesque imagery used to describe her postbirth, abject body (68-70). All this is to say that there is nothing necessarily obvious in Outer Dark's diegesis to suggest that Rinthy is forceful, or someone to be "reckoned with."

2 Attending to diegetic detail, however, is not the only way of working toward a textual interpretation. Sullivan herself attributes some of Rinthy's power to a more tonal and affective quality: "gravitas, the sort of dignity that prevents [Rinthy] from becoming ridiculous even in the most humiliating circumstances" (72). Sullivan rightly draws upon a range of narrative examples to explain Rinthy's enduring dignity, including the 
way she retains a sense of propriety even when she is shamed by other people (who, for example, insult and accuse her of engaging in illicit sex) (72). But the affective connotations of gravitas may not so easily be attributed to specific textual examples. We might speak about a person having a certain "air" or "sense" of gravitas: it can be a felt quality that a person or object or encounter seems to generate or emanate. Sullivan does not specifically speak about Rinthy's gravitas in affective terms but the choice of descriptor is nevertheless revealing, for it points to something about Rinthy that feels meaningful and significant, even if that significance seems at times disproportionate to the more obvious features of her characterization.

3 Sullivan is not the only McCarthy scholar to observe the mysterious power that Rinthy seems to generate. Anne Fisher-Wirth in "Abjection and the Feminine in Outer Dark" (2002) argues that McCarthy's female characters (with Rinthy as the example par excellence) become "more interesting the less he attempts to develop them, for their power is poetic, gestural" and proceeds to elaborate how Rinthy represents the power of abjection-a felt and bodily power-to ultimately resist the modes of rigid, symbolic categorization of patriarchy, represented by her brother $(127,137)$. Vereen Bell in The Achievement of Cormac McCarthy (1988) more specifically argues that Rinthy and the prose that describes her generate a feeling of meaningfulness, even though any actual meaning is difficult, if not impossible to comprehend, and positions a passage about Rinthy as exemplary of McCarthy's tendency to write prose that creates a "complex environment of suggestion" (2)-that is, feels intensely significant-even when the content appears strangely insignificant. According to Sullivan, Fisher-Wirth and Bell (and myself, as I will argue) there is something about Rinthy that seems very important and powerful, and, furthermore, such importance and power are bound up very much with how the reader feels and hence are somewhat resistant to traditional means of textual interpretation.

4 I should note that I am not suggesting that everyone responds to Rinthy in the same way. Jay Ellis, for example, argues that Rinthy's apparent narrative centrality is ultimately negated because McCarthy's primary interest lies in relationships between fathers and sons rather than women (No Place for Home 128). It remains the case, however, that certain aesthetic stimuli can inspire the same or similar feelings within a range of different people: Sianne Ngai in her work on literary tone observes that there is some "formal aspect" of literary works that can result in critics sometimes collectively responding affectively to texts in similar ways (43), and I have just outlined how Sullivan, Fisher-Wirth, Bell and I seem to agree that Rinthy feels forceful. As such there seems to be enough interest in Rinthy and her affective power to warrant further investigation. I am also not disposing of textual interpretation altogether. Heather Love has observed that even though scholars often assume that qualities such as literary "richness" exist (richness, and also tone, being elements of the reading experience usually sensed at least in part affectively, and at the level of the whole text rather than located in isolated instances of language), the mechanics of how those qualities are produced are often taken for granted and remain largely uninterrogated (371). Part of my aim in this paper is to try and account for the ways in which an example of McCarthy's prose might have particular affective effects: to work out what textual operations might result in particular experiences for some readers, and why.

5 My broader aim in this paper is to build on Sullivan's work by arguing that Rinthy is indeed a powerful "force," and to build on Bell's work by arguing that one of the most 
interesting aspects of Rinthy is the feeling of meaningfulness she generates. But instead of focusing solely on representational details to help explain her power, I focus explicitly on Rinthy's force upon readers. In other words, I am less interested in narrative examples that demonstrate any power Rinthy wields in a diegetic sense than I am in her tonal and affective resonance, a type of power that is not limited to the words on the novel's pages (even though it is generated through them) but is instead an interrelation between text and reader-an interrelation characterized by how the text makes a reader feel. To do this I will draw upon philosopher Brian Massumi's discussion of the centrality of affect in the process of interpreting images, particularly his theorization of the unpredictable and often illogical relationship between an image's semiotic content and spectators' felt reception of that content, in order to illuminate the way Rinthy's power is somehow felt as well as representational.

At the same time, I do not want to ignore the representational elements of Rinthy's characterization that may limit or compromise her power-particularly her power as a female character in a body of works that otherwise largely ignores the real lives of women. The fact that Rinthy is a powerful force might suggest that in Outer Dark, at least, McCarthy sees female as well as male bodies as participating in, and being moved by, the world. But the fact that the main drivers of Rinthy's power are affective (in terms of how she makes readers feel) and corporeal (in terms of her highly embodied characterization) raises questions around whether she, as a female character, somehow seems more corporeal, more embodied than McCarthy's male characters. If this is the case, we must ask: does Rinthy's affective power challenge McCarthy's latent misogyny, or is her power limited by her own representation, as well as what the text has to say about men? How might Rinthy's power be compromised by McCarthy's inability to totally elude the binary distinction between women and men across the polarities of body and mind, biology and culture? And, in Outer Dark, to what extent might the idea of an embodied femininity feed into American patriarchal ideas of sexual difference designed to oppress women on the basis of their biology, even if that biology is perceived as instinctually empathetic and outward-looking? In order to answer these questions, I examine the extent to which Rinthy's affective resonance overrides or is overridden by other elements of her representation; I also examine the way Culla seems to conceptualize sexual difference and whether his own anxiety around women and "the feminine" may be read as a critique of the male/female and culture/nature binaries, or whether the text indeed endorses such binaries.

\section{Massumi and Affect}

7 Before I move on to my discussion of Rinthy, I want to briefly recount Massumi's theory of affect and how it will be useful to my case. In "The Autonomy of Affect" (1995), Massumi describes affect as the autonomic bodily responses to stimuli that cause people to "feel" and goes on to explain what he calls the "the primacy of the affective in image reception" (84). "[T]he primacy of the affective is marked by a gap between content and effect," Massumi says, citing a study that found that children's emotional responses to a short film differed wildly and unpredictably from what was hypothesized. "It would appear that the strength or duration of an image's effect is not logically connected to the content in any straightforward way" (84). I argue that this 
apparent disconnect between content and effect is precisely the phenomenon that is strategically revealed through prose focusing on Rinthy, to varying degrees.

Massumi does not mean that conscious readings of images are not important or even integral to a holistic understanding of a spectator's response to an image. The semantic content of images is what inspires affect in spectators: feelings that occur when viewing an image cannot be separated from the image itself. However, Massumi cites several scientific studies which stated that spectators' immediate reactions to film can be most effectively measured through autonomic bodily responses such as heart rate, breathing, and galvanic skin response (a measurement of skin resistance that is an effective indicator of physical or emotional arousal). Crucially, these reactions occur involuntarily within the body's nervous system before the brain has consciously registered that it and the rest of the body are reacting to something, for "the skin is faster than the word" (86). This is why for Massumi (and other affect theorists will differ from him on this) affect is not an emotion, though it does contribute to emotion. Emotion, rather, is affect codified (88); emotions are feelings we have given names to in order to fit them into a linguistic logic, to contain them and to give them meaning. Affect, on the other hand, is the plethora of bodily responses that constitute our feelings prior to their expression in language.

My intent here is not to enforce the false but longstanding Western tradition of dichotomizing body and mind, or nature and culture, but rather to emphasize the body and mind's mutual interdependence in the process of aesthetic interpretation. Affect theory can be useful precisely because it confounds the traditional distinctions of body/mind and nature/culture by positing that meaning-making and interpretation occur not just rationally but materially, and in ways that we cannot always predict or control. Massumi cites a study that found that when patients were administered electrical impulses to either their skin or cerebral cortex, a half a second duration was the minimum time required for patients to consciously register they had received the shock (89). For Massumi, these results suggest there is a gap between the sensory processing of an image (or text) and the conscious registration of the image's reception and consequent interpretation-an "overfull" missing half-second "filled with motion, vibratory motion, resonation" $(86,90)$. One might say the half-second is filled by a force, though a force that may be directed any which way, since it is only once it is registered that such a force might be contained, narrativized or fit into a cultural logic or expectation.

10 It is right at this moment in between mind and body, brain and finger, outside and inside, materiality and culture, within or as the force-relation itself, where I argue that Rinthy's force originates. I argue that she feels significant and meaningful not because she signifies or means anything in particular but because she mimics the moment just before feelings become codified or can be expressed-that is, right before they are given meaning. She feels forceful because her effect mimics the intensity and resonance of the affective before it is consciously registered. Of course, the identification of this position or moment of in-between-ness is hypothetical to a degree, because while the missing half-second is a physiological phenomenon, it is theoretical in so far as our ability to recognize it as it happens. The transition from autonomic response to some sort of conscious aesthetic interpretation occurs so quickly that in terms of our actual experience, the transition is always already in the past and always feels integrated and simultaneous. But Massumi's theory of affect is a useful way of working through why 
Rinthy feels so important to several McCarthy scholars precisely because it describes the asignifying and often subtle nature of affect and yet foregrounds how integral affect and the bodily are to the process of meaning-making.

\section{Rinthy, Rhythm, and Texture}

11 I have chosen a couple of passages to help illuminate Rinthy's affective power. The first is the same as that selected by Vereen Bell in the introduction to The Achievement of Cormac McCarthy, whereby Bell positions the passage as a representative example of the “antimetaphysical bias" that characterizes McCarthy's work as a whole (Achievement 2). The prose is a short excerpt from a three and half page section of Outer Dark that describes nothing more than Rinthy getting ready for to bed. Here are some representative paragraphs:

She laid her bundle down on the bed and took the lamp and the basin and the soap and went out, holding the lamp votively before her and the heat rising pleasantly about her face. She watched the ground, going with care, the basin upright and riding her hip, slowly, a processional, a lone acolyte passing across the barren yard, face seized in the light she bore. (62)

....

She took the soap and lathered her hands up in a gritty curded paste, spreading it over her face and then dashing cold water after it, eyes shut fiercely against the soap's caustic sting. When she had finished she rinsed the basin and took up the lamp from the ground and started for the house. The whippoorwill had stopped and she bore with her now in frenzied colliding orbits about the lamp chimney a horde of moths and night insects. (63)

....

She turned down the lamp and removed her dress and hung it over the brass bedpost. Then she unrolled the shift and put it on and crawled into the bed. She lay on her back very quietly for several minutes, her hands clasped above her stomach, feeling the slack flesh beneath her shift. Then she sat up and cupping her hand behind the lamp chimney blew out the light.... She turned carefully on her rattling pallet. She listened for a bird or for a cricket. Something she might know in all this dark. (65)

Bell's use of this passage as exemplary of a whole oeuvre might initially seem somewhat unlikely. The scene, which takes place at the small, rustic house of a family who has taken Rinthy in for the night, is, as Bell himself notes "autonomous and involves no foreshadowing" (Achievement 3): it seems decontextualized and extraneous to the actual plot, for even though it lasts many pages, nothing much happens in it other than Rinthy completing her ablutions before sleep. I would add that the scene is in no logical or conventional way relevant to Rinthy's search for her child, which is otherwise the driving force of her narrative. In fact, unlike almost every other scene that focuses on Rinthy in the novel, this one barely even references the fact she is a mother, apart from one brief mention of the "slack flesh" of her belly in the passage's penultimate paragraph (Outer Dark 65). Even though the scene might not appear to fit into the narrative of Outer Dark as a whole, at least in a conventional sense, and so might seem an odd choice for the passage that (for Bell, at least) best sums up McCarthy's approach to the primacy of the material, it is precisely the way this passage resonates in spite of, or perhaps because of, its extraneousness that renders it useful for Bell's-and my own -argument. 
13 I suggest that there is an affective intensity about the passage that seems to exceed its content. That is, the power of this passage cannot be solely articulated through traditional semiotic interpretive strategies. Even though the content could be seen as ordinary or mundane, or extraneous, or even pointless or bland, there is something appealing about the passage, something soothing and seductive; something that makes it feel very evocative even though it is hard to say exactly what it evokes, apart from a type of calm rhythmic sensation, and, as I will elaborate, a sense of texture. That is not to say that the symbolic elements do not contribute at all to these effects; on the contrary, there is something about this particular combination of words in this particular story that evokes particular feelings. It is just that there is not necessarily a conventional logical relation between signifiers and the physical responses they might induce.

14 It is possible that Rinthy feels meaningful in part because the prose that describes her in the above excerpt mimics the rhythms of autonomic bodily processes that contribute to interpretations and understandings of the world. Some of the autonomic functions that Massumi ascribes to affect include breathing and heart rate, two functions that are often measurably altered when encountering art and affect our interpretation of that art, even if we do not realize it. I argue that a sense of bodily rhythm that is formed through the passage's repetitive syntax, as well as its undulating sentences and focus on sensory experience.

15 The simple style of this passage about Rinthy seems to create a gentle rhythm that is formed perhaps most obviously through a syntactic pattern comprised of declarative sentences and clauses that position Rinthy as the subject completing simple tasks expressed primarily through transitive action verbs. In the paragraphs quoted above, we see examples such as "She laid her bundle" (Outer Dark 62); "[she] took the lamp and basin and soap" (62); "[she] went out" (62); "she watched the ground" (62); "she took the soap" (63); "she rinsed the basin" (63); "[she] took up the lamp" (63); "[she] started for the house" (63); "she turned down the lamp" (65); "She lay on her back" (65); "[she] removed her dress and hung it over the brass bedpost" (65); "she unrolled the shift and put it on and crawled into the bed" (65); "She watched them" (65); "She turned carefully on her rattling pallet" (65); "she sat up and cupping her hand... blew out the light" (65); "She listened for a bird or for a cricket" (65). Other examples from the parts of the passage not quoted include: "She found the well" (63); "She bore with her now in frenzied colliding orbits" (63); "she heard the rattle" (63); "She was upon the steps" (63); "She paused" (63); "she looked up at a sky heavy and starless" (64); "She watched him" (64); "[She] watched him above the glassrimmed flame" (64); "[she was] already mounting the steps" (64); "she put the lamp on the shelf" (64); "[she] sat on the bed" (64).

16 These declarative, simple sentences do not occur with a particular regularity in that they do not form an exact pattern, but they are regular enough that they form a sort of soft rhythm. Breathing and heart rate might be pattern-based functions, whose effectiveness relies on repetition and continuousness, but that does not mean that every iteration of the pattern is the same. Rather, breathing and heart rate are (often unpredictably) changeable and forever modulating-sometimes obviously, sometimes minutely-alongside and within any given situation or context that a body might be in. (The type of declarative prose style seen above is not unique to descriptions of Rinthy, nor even to Outer Dark, but its effect is very different to say, a novel like No Country for 
Old Men (2005), where an otherwise similar style has a far more aggressive and relentless impact). The beat in the passage from Outer Dark seems to fall on the pronoun "she," which is almost always positioned as the active subject; it also emphasizes the correlating verb. As a result, both Rinthy's subjectivity and her bodily capacity are foregrounded, not just in place of her inner thoughts but in place of what might be called narrative "depth" or metaphor. That is, the writing foregrounds the minute movements of bodies in a world and contains observational descriptions that do not seem to mean anything apart from what they actually say: as Bell describes it, in "McCarthy's novels... the world itself is mysterious enough without involving ideas or transcendence of it" (3).

The passage also creates a sense of texture, almost like a patterned surface or tactile environment we could run our hands over. If Massumi describes affect as the bodily processes that occur between brain and finger, then what the finger touches must necessarily inflect those processes and the subsequent conscious registration of whatever surface the finger has encountered. Texture, or rather the experience of encountering textures, is understood by affect theorists as contributing to the material potential both of bodies and the world-indeed, the potential of the force-relations between the two-and as being integral to the way we make meaning. ${ }^{1}$

The passage about Rinthy can be perceived as textural because it is laden with what I call "flashes" of sensory language, with a focus on haptic terms, that emphasize Rinthy's interactions with the world around her. Haptic language is especially significant, since in 2011 a study found that the texture-selective somatosensory cortex -the part of the brain that that is activated when we physically touch something and perceive a texture-is activated when processing textural metaphors. Using fMRI, scientists compared the brain activity of participants as they read textural metaphors (such as "weighty matters" or "coarse language") as well as literal sentences with the same meanings. It was only whilst reading the textural metaphors that the somatosensory cortex was activated. The scientists concluded that the study provided good evidence for suggesting that abstract knowledge is perceptually grounded (Lacey et al. 416-420).

The "gritty" paste of the soap, the "caustic sting" as it hits her eyes, the blast of "cold water", the "warmth" of the candle about Rinthy's face: these moments in particular create not only sensory flashes within the story, but jump out at readers, too. Consider also that Rinthy feels the "cool night air" (Outer Dark 61); hears the "whippoorwill calling... and hushing" (61); perceives the "[w]arm reek of the room" (62); "heat rising pleasantly about her face" (62); hears the "hoarse gasp" of the pump" (63); feels the "long pull" of the water pumping (63); hears "the rattle of his canvas breeches" (63); senses the "false warmth' of the storm" (64); hears "dry brittle sound" of the shuck tick (64-65); and "listened to [the family] breathing" (65).

Even though the parallel is not identical, I wonder if the recurrence of sensory and haptic terms in the passage about Rinthy may have an effect on readers similar to the effect the textural metaphors had on the participants of the study mentioned before. The rhythmic patterns in the passage as well the regular haptic flashes might contribute to the passage feeling solid and textural like a surface, rather than like a conventional text with interpretative or symbolic depths, because they literally activate the part of brain used in processing actual, material textures. And, if we take our cues from Massumi and Sedgwick, who suggest that the affective consequences of 
touch and texture are integral to narrativizing and making meaning in the world, it is possible to read the passage about Rinthy as generating a sense of meaning because reading it mimics the moment in between brain and finger, the impossible point between inside and outside, self and other, right before our interactions with the material become abstracted.

21 Furthermore, the fact that the passage presents a body's subtle movements in ways that evoke rhythm and texture seems to be designed to draw attention to the passage's affective power. I am not the first to describe McCarthy's prose as textural: Kenneth Lincoln, Dianne C. Luce, Thomas Young, David Holloway, Vereen Bell, and Steven Frye have all at different points used the concept of texture quite specifically to describe the sense of the concrete and material world that McCarthy's prose elicit. ${ }^{2}$ But it is perhaps rare that such an otherwise strangely positioned and extraneous passage should so clearly generate a series of affects, to the point where creating affective resonance seems its sole purpose.

The more calming and hopeful effects of the passage about Rinthy might have something to do with the fact that the passage, unlike many other passages in Outer Dark, is devoid of fearful acts or characters and the sense of doom that pervade Culla's or the Grim Triune's storylines. But I think it has more likely to do with the close attention to extraneous detail in the passage and the somewhat decontextualized descriptions of Rinthy completing small and ordinary tasks, descriptions which seem to foreground the minute and subtle modulations bodies that are inherent to life but not always noticeable. That said, I want to suggest that the focus should not remain solely on Rinthy's sensory experience, nor even on any one element of the scene as a discrete, individual occurrence or moment. It is as if the passage needs to be absorbed in its quantum according to the overall impression that it leaves rather than as part of Outer Dark's diegesis or even as a decontextualized vignette about a certain character. The passage, I suggest, is not really about the soap or the water or the candleflame per se, and perhaps not even strictly about Rinthy preparing for bed, but about the sense of vibration and resonance that readers might observe or feel. In this way, the passage might feel meaningful without meaning anything in particular because it mimics some of the autonomic bodily rhythms that inflect our understanding and interpretation of the world just prior to their incorporation into language and conscious understanding -just prior to making meaning.

As such I do not entirely agree with Bell that McCarthy's work demonstrates an "antimetaphysical bias," a phrase that implies not only a preference for the concrete but a type of opposition to the abstract, an implication Bell emphasizes when he states that in McCarthy's work, "the world is mysterious enough without involving ideas or transcendence of it" (Achievement 3). I would suggest a slightly different interpretation. To me, the passage about Rinthy is less about opposing transcendence and more about a working through of the ways in which ideas of the metaphysical might be generated; that is perceptually, sensorially, materially. It is about the ways in which the material and the abstract are inseparable and mutually interdependent. Ideas here seem to emerge from the material, where materiality is understood as dynamic rather than static, as part of an infinite feedback loop with the abstract. Perhaps McCarthy's work is not best characterized as antimetaphysical, but instead as interested in foregrounding the centrality of the material in the process of meaning-making and abstraction. Perhaps Rinthy feels significant to some McCarthy scholars because she 
embodies embodiment; the physiological processes which, when consciously registered, go on to direct and shape our behavior and thoughts, and contribute to our understanding of the world. She feels significant because she represents that interface; that liminal and dynamic moment in which feelings are translated into meaning, by which I mean registered by the brain and expressed through language. The process of reading about Rinthy, in this passage at least, and responding to her as a reader mimics the unpredictable, unrecoverable affective moment when alinear, autonomic bodily responses enter conventional structures of meaning.

\section{Implications for Reading Gender in Outer Dark}

It is important to highlight that despite my focus on bodily rhythms and sensory perception, I do not suggest that Rinthy, based on her affective resonance alone, should necessarily be reduced to her body or its so-called "natural" functions at the expense of her subjective independence. Rather, by positioning a section of text about Rinthy as powerful in an affective sense I aim to demonstrate the interrelatedness and mutual interdependence of oppositions such as mind and body, and nature and culture; to argue that Rinthy's body (in the above passage, at least) is a site of open-ended potential, a radically open-ended and dynamic type of body that changes and is changed by the rest of the world.

That said, it is important to ask two further questions concerning Outer Dark. Firstly, is Rinthy's dynamic, affective power limited by other representational details? And, secondly, does the rest of Outer Dark-that is, Culla's story-support the notion of women being able to exist as independent subjects with dynamic bodies, rather than as an essentialized category that is reduced to a static body?

Since Outer Dark is divided into two distinct plotlines-one focusing on Rinthy, and one on Culla-scholars often read the story as exploration of certain binaries, with opposing terms or concepts emphasized in each plotline. Luce speaks of darkness and light (Reading the World 75-83); Bell of word and flesh (Achievement 35); Fisher-Wirth of symbolic and real (133): these binary pairs are often-and quite rightly-deployed when discussing the differences between Rinthy and Culla's stories. Rinthy is usually seen to represent the latter term in each of these pairs-that is, she is usually associated with the bodily and the material, and such observations are warranted. Early in the story, Rinthy is described as walking out of the woods with "halt corporeality" (Outer Dark 97) and this description accurately foreshadows her characterization throughout the rest of the narrative. The labor and birth of her child are described graphically, with a focus on her writhing body, the way she clings to the bedposts, and the amount of the blood she loses (13-14). Throughout the rest of the story she experiences vaginal bleeding and leaks breast milk, usually when she is speaking about her child (32-33, 99, 152153). She is also never psychologized-that is, we are never told what she is thinking or feeling-and the focus is always on her body and physical movements. Her brother Culla is also not psychologized in this way, however, as Luce has noted, it is possible to read Culla's story or indeed the entire world of Outer Dark as an external manifestation of his psyche (Reading the World 62). As such, Culla may be associated with the mind, and Rinthy with the body in direct contrast to him. In this sense, it can be tempting to view Rinthy's association with materiality and a distinct lack of metaphysics as well as her position as a mother whose reproductive organs are figured as leaky or unruly, as 
problematic from a feminist perspective, since historically in the West, women's perceived affiliation with nature and biology (rather than with the usually privileged terms of culture, language and the mind) has been used to justify their oppression across various times and cultures. This is why Sullivan, I think, is wary of attributing too much agency and power to Rinthy.

But unlike Culla, who seems to wander the landscape purposelessly, Rinthy has a clear and pragmatic purpose: to find her son, to the exclusion of almost all other activity. This points firstly toward something like her innate maternal instinct, a willingness to sacrifice everything including her own welfare for her child, which again can be seen as problematic since it essentializes her to what Fisher-Wirth calls "body and patience" (132). But Rinthy's consuming desire for her child is also one of her main points of difference with Culla. Rinthy is outward-looking rather than inward-looking, and actively looks for human connection where Culla cannot; she is able to see her child as a person who requires care rather than as a symbol of her own shame. She is also associated with light. As Luce has observed, Rinthy remains protected by an "amnion of light" that she seems to generate, and is associated with "light in its more usual senses: benediction, grace, insight, and a force in opposition to darkness" (Reading the World 80). Rinthy is often accompanied by sunlight or lamplight, and these literal lights function almost metonymically for the "goodness" that seems to permeate her relations with other people, which, as Lydia Cooper has noted, are almost always sympathetic and reciprocal. In fact, most readings of Outer Dark (even Sullivan's) position Rinthy as the more positive, likeable, and productive character in the story in comparison to her brother Culla. Cooper in No More Heroes: Narrative Perspective and Morality in Cormac McCarthy (2011) actually argues that Rinthy functions as the narrative's moral center, not in a rigid or didactic sense but through the way Rinthy seems designed to inspire empathy in readers. Furthermore, McCarthy seems to be, if not deeply critical of Culla, then at least warily ambivalent toward him: Culla is not a sympathetic character, either to the people he interacts with in the story or to readers, and his journey consistently leads him along paths of violence, absurdity, darkness, and eventually the literal and figurative dead end of the miry swamp, the place where the road runs out. As such, Rinthy's characterization as a woman creates a strange tension, because on the one hand she is problematically essentialized, but on the other, she still seems to be positioned as the source of hope or "goodness" in contrast to the doomed male of the text.

Nevertheless, Rinthy's caring and empathetic nature sound in some ways promising for a reading of sexual difference: to whom does a selfless outlook look less appealing than a selfish one? However, as Linda Alcoff has noted, "woman" has historically been perceived as an

essential something... Despite the variety of ways in which man has construed her essential characteristics, she is always the object, a conglomeration of attributes to be predicted and controlled along with other natural phenomena. The place of the free-willed subject who can transcend nature's mandates is reserved exclusively for men. (Visible Identities 134)

From Puritan ideas of women as the "vessel" to the nineteenth century Cult of True Womanhood, to twenty-first century neo-conservative conceptualization of the "security mom", one strand of what it means to be a woman in America has been strongly inflected by ideals around motherhood and empathy and that women are essentially virtuous and empathetic. The representational details that characterize 
Rinthy seem to lend themselves to these ideas (she will not stop at anything to find her child, she naturally connects with other people, she can be read as the moral center of the novel) and even though Rinthy's affective power might be strong enough to override some of these details to a degree, we must examine whether the rest of Outer Dark supports the notion of an essentialized womanhood or not. I will do this by exploring the way that Culla conceives of sexual difference and whether the text is truly critical of that conception or not.

One way of understanding sexual difference in Culla's storyline is to read Culla's journey as similar to that of a traditional mythic male protagonist. Jurij Lotman argues the trajectory of the male mythic hero can be reduced to two single events that are endlessly repeated and reproduced: "entry into closed space-emergence from it (this chain is open at both ends and can be endlessly multiplied)" (168). Entry into the closed space usually constitutes the challenge for the hero to overcome, and the hero's emergence from the space signifies 'rebirth and rejuvenation" (169). That is, there is a redemptive element in the hero's emergence from the enclosed space.

While Lotman never states this explicitly, there is a particular form of sexual difference operating in his account of myth, which can be inferred from the way he genders the dark, enclosed space through which this male hero moves: "Inasmuch as closed space can be interpreted as 'a cave,' 'the grave,' 'a house, 'woman,' (and, correspondingly, be allotted the features of darkness, warmth, dampness) ... entry into it is interpreted on various levels as 'death,' 'conception, 'return home' and so on; moreover all these acts are thought of as mutually identical" (168). Like Culla's "vulvate welt," the concept of "women" in Lotman's formulation of myth becomes synonymous with dark spaces or topography, since "woman" is the same as caves, graves, and houses. This concept of woman is also bodily. Since the dark, warm damp space that the hero must enter and emerge from in order to be reborn is also female, Lotman actually figures this space as a womb-space.

Outer Dark seems to rewrite this configuration of sexual difference through the way that Culla's encounters with the enclosed space of the womb result in darkness and dead ends rather than redemption and rejuvenation. Culla regularly enters spaces of darkness or enclosure that resemble the "“"cave, "the grave," "a house," "woman,... darkness, warmth, dampness" of which Lotman speaks. Where Lotman's mythic hero moves into an enclosed space and then emerges from it reborn or resurrected, Culla emerges only into greater darkness and is repeatedly thrust into one terrifying space after another even though he appears to go through a symbolic process of rebirth prior to each spatial relocation. The opening lines of Culla and Rinthy's story establish this sequence of events for Culla, as Rinthy awakes him from a nightmare: "She shook him awake into the quiet darkness... She shook him awake from dark to dark, delivered out of the clamorous rabble under a black sun and into a night more dolorous, sitting upright and cursing beneath his breath in the bed he shared with her and the nameless weight in her belly" (Outer Dark 5). Here, Culla moves from "from dark to dark" as he awakes from a bad dream containing a "black sun" into a "night more dolorous." Culla's transition from dark to dark is facilitated by Rinthy: that is, by a woman. Not only does Rinthy wake Culla, she "delivers" him, an action evocative of birth. Importantly, Rinthy is only known as "she" at this point in the narrative (her name is not revealed for several chapters) lending her presence a somewhat ephemeral air, rather than signifying a concrete, female person. As such, Culla appears as a mobile 
character undergoing a shift in location (dark to dark), while Rinthy remains an unnamed female presence that is a catalyst for male movement, through aiding his socalled delivery, or rebirth. One may argue that because Culla's name is also not yet revealed, he should not yet be seen a concrete person either; however, Culla's name is spoken by Rinthy only two pages later, and the long, almost elaborate sentence in the quotation above describing Culla's relocation from nightmare to waking reality seems to foreground his experience and action in this scene, rather than Rinthy's, whose action of shaking Culla awake is explained in only four brief words ("she shook him awake").

The opening sentences of Rinthy and Culla's story actually prefigure the pattern of Culla's movement throughout the rest of the text. Consider the dark space of the forest that Culla moves through after Rinthy has given birth and he has kidnapped the child. Even though Culla flees the cabin with the child before sundown, the forest path is described as "banded with shadow, dark beneath the pine... Shadows which kept compass against all the road's turnings" (McCarthy, Outer Dark 15). Not only is the forest dark and shadowy for Culla before the sun has even set, but the shadows are his "compass," guiding and directing him; soon, the forest brims with imagery evoking birth and even female genitalia. He "took a path along the river, the swollen waters coming in a bloodcoloured spume from about the wooden stanchion" (15), echoing the "pumping welter of blood" (14) that burst from Rinthy as the baby was born. He then flounders "through sucking quagmires" (16-17), and this description of the swampy landscapes prefigures the "mire" he comes to on the novel's final page, which "rose in a vulvate welt claggy and sucking" (242). The forest finally becomes a birthing chamber for Culla, after he crashes through the glade where he abandons his child:

$[\mathrm{H}] \mathrm{e}$ fell headlong and lay there with his cheek to the earth. And as he lay there a far crack of lightning went bluely down the sky and bequeathed him in an embryonic bird's first fissured vision of the world and transpiring instant and outrageous from dark to dark a final view of the grotto and the shapeless white plasm struggling upon the rich and incunabular moss like a lank swamp hare. He would have taken it for some cognate of his heart's own dread, had the child not cried. (17-18)

This scene not only depicts the convergence of darkness and the female through Culla's figuration as a newly born bird, but clearly demonstrates the horror Culla experiences at each instance of rebirth. Rather than being renewed, rejuvenated or redeemed as he emerges from the darkness, Culla is petrified by the vision of his own rebirth, which he sees in the form of his own son.

The dark spaces through which Culla's moves are not only feminized, but are comprised of disorder, horror and indiscreteness. At one point, Culla arrives at a ferry to cross a wide river in the woods. The "vulvate welt" is immediately conjured through the mud which surrounds Culla the ferryman on the river bank: a rider goes past in a "mudsucking canter" (156); and the ferryman wade through mud up to his knees (159). The ferry itself is also referred to as "she" numerous times, and the feminized boat is again the catalyst that Culla rides into darkness. Once on the ferry, the river and darkness merge into a terrifying image of the topologically infinite. "The river was dark and oily and it tended away into nothing, no shoreline, the sky grading into a black wash... so that they seemed to hang in some great depth of darkness like spiders in a well" (164). And "She goes right along, don't she," Culla calls at one point, but soon after the ferryman is washed overboard, the darkness and river threaten to subsume 
Culla too. This blackness is a vacuum, a place of nothingness that has absorbed not only sound and space but all movement, except for a terrified and horse, disembodied since Culla can only hear its gallop, which careers around the deck till it too is washed away. Toward the end of this ordeal, Culla is left "sitting helpless and blind, clutching the bench, his stomach lapsing down black and ropy glides and the fog cold and wet upon him, praying silent and godless in his heart to the river to be easy" (167). He sees light; but is no true light at all, just a "pin-flicker set in a glozed cup", the campfire of the Grim Triune who are waiting to greet him upon the spit of land on which Culla finally alights.

It may be possible to read Culla's story as a critique of white, anxious masculinity and the corresponding understanding of women as space and body rather than as real people, since Culla's journey is ultimately one of failure and despair. The implication of the text seems to be that men are naturally egocentric, trapped in a symbolic world of their own dread and anxiety which occurs in part as a result of their understanding of sexual difference, and that women are naturally and biologically more ethical and outward-looking. While it seems obvious that the latter is more appealing-most people would probably value empathy over self-absorption-the fact that these states are presented as natural (women's natural state is corporeal and men's natural state is symbolic) ultimately remains unchallenged by the story, even if the story reveals some negative effects of such a conception of sexual difference.

Furthermore, any critique of the binary of male/female across the symbolic/material division seems subordinate to the exploration of the male anxiety that might occur as a result of that binary. Not only does Outer Dark literally begin and end with Culla's movements, but Rinthy's own dynamic, material agency is slowly diminished as the story proceeds and the symbolic encroaches on the more grounded prose style that normally describes her. Toward the end of the novel there is a linguistic shift in tone that permeates Rinthy's sections of the text, a shift that perhaps suggests her power will eventually wane, or is unsustainable in the long term. Consider the scene where she appears to be staying with a farmer, who becomes upset that she will not engage with him (it is unclear whether his intentions are sexual or not-primarily he seems frustrated that she is uninterested in even speaking to him at a basic level [Outer Dark 210]). Here, Rinthy retains a strength within the diegesis through what Sullivan calls "the power of yes and no" ("Dead Girlfriend" 71), which is in part Rinthy's ability to withhold her erotic potential from the men she encounters. Rinthy refuses to acknowledge the farmer at all: she walks past him "wordlessly" (McCarthy, Outer Dark 209); serves him dinner in silence (210); only swings "her eyes vaguely toward him" when he speaks to her (210); and leaves the table to go to bed with an abrupt "goodnight" after he practically begs her to say anything at all, even just "hello or goodbye" (210). Rinthy might be described as "wooden" and "doll-like" (Sullivan refers to such terms as "misogynist details" [68]) but in this scene her mechanical movements seem more to do with her reluctance to connect with the farmer and instead to continue the urgent task of finding her son, rather than some essential element of her characterization. In the next section of text, Rinthy secretly leaves the farmhouse in the night.

Sullivan is also clear, though, that Rinthy's power of yes and no is evidence of her ability to define and pursue her own desires more broadly-that is, not just in terms of men ("Dead Girlfriend" 71)-and I argue that in this passage, Rinthy's general agency is 
enhanced by the textual strategies (and their effects) utilized by McCarthy in the earlier passage where she prepares for bed. That is, this passage primarily describes Rinthy and her actions using the pronoun "she" in the active position that are either short, independent clauses ("She sat quietly by the rocker" [209]; "She started past him toward the door" [210]) or longer compound sentences comprised of simple independent clauses ("She took her few things from the chifforobe and bundled them and went to the landing beyond her door" [211]); the narrative focus is consistently on Rinthy's body and its small movements in space ("She rose and went in... her slippers like mice along the dark hallway" [209]; "She crouched in the dark long and long... and when she did descend the stairs in her bare feet she paused again at the bottom in the dead black foyer and listened up the stairwell" [211]; the sentences are frequently punctuated with sensory language and description ("smelling the rich ground" [209]; "She heard him in the house"[209]; "the wooden clap of the door closing" [210]; "she could hear roosters" [211]). Since these syntactic forms are used almost to the exclusion of other sentences types and foci, the combination of all these elements creates a similar rhythmic pattern to the passage in which Rinthy prepares for bed, though the effect of that rhythm is perhaps slightly different. As I argued earlier, the creation of a material and bodily rhythm and texture, felt affectively by the reader, may be read as the sole purpose of that first passage; here, the rhythm and affective momentum serve more to highlight the diegetic power and agency Rinthy demonstrates.

But deeply symbolic language soon begins to impinge on both the prose describing Rinthy's journey, and even upon Rinthy herself as her fear increases and any likelihood of her reaching a "happy" ending almost completely diminishes. We see this first in the way the farmer crushes a moth in his hand after Rinthy retires for bed: Rinthy is frequently associated with moths and other insects (see Outer Dark $54 ; 59 ; 63 ; 64 ; 98$ ) and so the metaphor for Rinthy's own impending "crush" is almost ludicrously obvious. Secondly, at the end of this passage, Rinthy is pursued by a horse on the road, though a real or symbolic horse it is difficult to say, since it is "in a silhouette agonized to shapelessness" (212); in fact, the figure of the threatening horse threatens the amorphousness and darkness of the female presence that haunts Culla throughout his narrative, suggesting that even Rinthy, with all her material and affective agency, will soon be subsumed by the conception of woman that stunts Culla. In fact, as the horse disappears down the road, sensory perception seems to fade altogether into a vacuum: "the sound of [the horse] dying down the road to a distant echo of applause in a hall forever empty" (212).

While the exploration of affect and the dynamic body is potentially quite radical in Outer Dark because it takes place through an embodied female character, hence foregrounding her personal experience and a non-binary way of conceptualizing embodiment, subjectivity and experience, Outer Dark still ultimately upholds the difference between male and female, or between men and women, as an essential difference based on a material/symbolic distinction. The powerful effects of Rinthy are complicated by the fact that her empathetic nature, as seen diegetically and affectively, seems innate and natural far more than it seems an example of a female subject who just happens to be an ethical person. That is not to say that Rinthy's powerful effects and affective resonance should be ignored: indeed, they are hugely useful in thinking about the ways in which she does feel powerful, particularly in comparison to later female characters in McCarthy's novels, such as the dead female bodies in Child of God 
(1973) or even Magdalena in Cities of the Plain (1998). Rinthy is still, to my mind, the most productive female character in McCarthy's oeuvre to date and demonstrates at the very least McCarthy's ambivalence or uncertainty toward whatever it might mean to be a woman in the world, and she can be seen as a gesture toward productive ways of working through affective ways of being for both women and men. That said, McCarthy does not entirely escape the sexist traditions that have sought to characterize American women for centuries-the idea that they are natural mothers, innate caregivers, and essentially empathetic and self-sacrificial in nature.

\section{BIBLIOGRAPHY}

Alcoff, Linda Martín. Visible Identities: Race, Gender, and the Self. Oxford: Oxford University Press, 2006. Print.

Arnold, Edwin T. and Dianne C. Luce, eds. Perspectives on Cormac McCarthy. Jackson: University Press of Mississippi, 1999. Print.

Bell, Vereen. The Achievement of Cormac McCarthy. Baton Rouge: Louisiana State Press, 1988. Print.

---. “The Ambiguous Nihilism of Cormac McCarthy.” Southern Literary Journal 15 (1983): 31-41. Print.

Cooper, Lydia R. No More Heroes: Narrative Perspective and Morality in Cormac McCarthy. Baton Rouge: Louisiana State University Press, 2009. Print.

Ellis, Jay. No Place For Home: Spatial Constraint and Character Flight in the Novels of Cormac McCarthy. New York: Routledge, 2006. Print.

Fisher-Wirth, Anne. "Abjection and 'the Feminine' in Outer Dark." Cormac McCarthy: New

Directions. Ed. James Lilley. Albuquerque: University of New Mexico Press, 2002. 125-40. Print.

Frye, Steven. Understanding Cormac McCarthy. South Carolina: University of South Carolina Press, 2009. Print.

Holloway, David. The Late Modernism of Cormac McCarthy. Westport: Greenwood Press, 2002. Print. Lacey, Simon, Randall Stilla and K. Stathian. "Metaphorically Feeling: Comprehending Textual Metaphors Activates Somatosensory Cortex." Brain and Language 120 (2012): 416-421. Web. 4 Nov. 2017.

https://www.ncbi.nlm.nih.gov/pmc/articles/PMC3318916/

Lincoln, Kenneth. American Canticles. New York: Palgrave Macmillan, 2009. Print.

Lotman, Jurij. “The Origin of Plot in the Light of Typology.” Trans. Julia Graffy. Poetics Today 1:1/2. (1979): 161-184. Print.

Love, Heather. "Close But Not Deep: Literary Ethics and the Descriptive Turn." New Literary History 41. 2010. 371-391. Print. 
Luce, Diane C. “Cormac McCarthy's First Screenplay: ‘The Gardener's Son.” Perspectives on Cormac McCarthy 1999. 71-98. Print.

---. Reading the World: Cormac McCarthy's Tennessee Novels. Columbia: University of South Carolina Press, 2009. Print.

Massumi, Brian. "The Autonomy of Affect." Cultural Critique 31.2 (1995). 83-109. Print.

McCarthy, Cormac. No Country for Old Men. 2005. New York: Vintage, 2007. Print.

---. Outer Dark. 1968. New York: Vintage, 2007. Print.

Ngai, Sianne. Ugly Feelings. Cambridge: Harvard University Press. 2005. Print.

Sedgwick, Eve Kosofsky. Touching Feeling: Affect, Pedagogy, Performativity. Durham: Duke University Press, 2003. Print.

Spinoza, Benedict de. Ethics. Trans. Edwin Curley. London: Penguin, 1996. Print.

Sullivan, Nell. "The Evolution of the Dead Girlfriend Motif in Outer Dark and Child of God." Myth, Legend, Dust. Ed. Rick Wallach. Manchester: Manchester University Press, 2000. 68-77. Print.

Young, Jr. Thomas. D. “The Imprisonment of Sensibility: Suttree." Perspectives on Cormac McCarthy. Eds. Edwin T. Arnold and Dianne C. Luce. Jackson: University Press of Mississippi, 1999. 97-122. Print.

\section{NOTES}

1. Eve Sedgwick in Touching Feeling paraphrases Renu Bora to describe the way texture functions as a contextualizing force: "to perceive texture is always, immediately, and de facto to be immersed in a field of narrative hypothesizing, testing and reunderstanding of how physical properties act and are acted upon over time" (13).

2. See Lincoln (43); Luce (Reading vii, 62); Luce ("First Screenplay" 75); Young (97); Holloway (88); Bell (1983, 37); Frye (3).

\section{ABSTRACTS}

Cormac McCarthy's 1968 novel, Outer Dark, is arguably his only text that contains a true female protagonist. Rinthy Holme is a significant character in her own right, in part because almost half the storyline is dedicated to her, but also because she seems to generate what scholars have referred to as a sense of forcefulness or meaningfulness that is sometimes at odds with otherwise more problematic elements of her characterization. By focusing on a small excerpt of Outer Dark, I argue that Rinthy feels meaningful because of the affective resonances that the text that describes her seems to emanate, rather than solely as a result of any diegetic aspect of her characterization. I draw on Brian Massumi's account of affect to illuminate the apparent disconnect between the content of the text about Rinthy and its actual physical effects on readers, as well as the textual operations that might cause these effects. I also investigate, however, whether Rinthy's affective power is truly able to combat other more problematic 
elements of her characterization, such as her apparently essentialized maternal instinct and empathy. I conclude by arguing that although the excerpt analyzed demonstrates a powerful instance of McCarthy's interest in the centrality of the material in the process of meaningmaking, and also perhaps suggests that McCarthy gestures towards the ways in which women might engage in the world as independent, embodied agents, McCarthy ultimately cannot escape an essentialized male/female binary.

\section{INDEX}

Keywords: Cormac McCarthy, Outer Dark, affect, feminism

\section{AUTHOR}

\section{JULIA TULLOH HARPER}

Julia Tulloh Harper is a PhD student at the University of Melbourne, where she also teaches 19th Century American Literature. Her dissertation focuses on masculinity in Cormac McCarthy's fiction. 